\title{
The Role of Facial Attractiveness and Gender on Change Detection and Recognition Memory
}

\author{
Özlem Ertan-Kaya ${ }^{1}$
}

Ertan-Kaya, Ö. (2021). The role of facial attractiveness and gender on change detection and recognition memory. Nesne, 9(21), 481-494. DOI: 10.7816/nesne-09-21-01

\section{Keywords}

Change detection, facial attractiveness, recognition memory, automatical attention gender differences
Anahtar kelimeler Değişim saptama, yüz çekiciliği, tanıma belleği, otomatik dikkat, cinsiyet farklılıkları

\begin{abstract}
This study aimed to investigate the effect of automatic attentional bias on change detection and recognition memory performance. In this context, attractive faces, which have priority in attention selection, were used as stimuli. The data of 110 participants were analyzed (54 females, 56 males, $M_{\text {age }}=20.87 \pm 1.80$ ). As a result, there was a significant effect of attractiveness $\left[F(2.73,295.16)=37.33, p<.001, \eta_{p}{ }^{2}=.26\right]$ and model gender $[F(1$, $\left.108)=6.47, p<.05, \eta_{p}{ }^{2}=.06\right]$ on change detection performance. Accordingly, the fastest performance is when only the target was an attractive female; the slowest performance was observed when only the distractors were attractive female. On the other hand, the data of 94 participants (46 females, 48 males, $M_{\text {age }}=21.05 \pm 1.95$ ) were analyzed for the recognition memory. Accordingly, low memory performance was generally observed. Memory sensitivity was significantly lower for attractive faces (-.31) than average-looking ones (.59). Besides, bias to respond "old" for attractive faces were higher than average-looking faces for both model genders. Therefore, the findings suggest that the decision criterion was more liberal for attractive faces (for females -.06, for males -.46) than average faces (for females .15, for males .33). On the other hand, there was no significant effect of the participant gender on both attention and memory tasks $(p>.05)$. The study is the first known change detection and recognition memory study to examine participant gender, model gender, and attractiveness together. The limitations of the study and suggestions for future studies are handled in the discussion section.
\end{abstract}

\section{Yüz Çekiciliği ve Cinsiyetin Değişim Saptama ve Tanıma Belleği Üzerindeki Rolü}

$\ddot{\mathbf{O} z}$

Çalışmanın amacı, otomatik dikkat yanlılığının değişim saptama ve tanıma belleği performansı üzerindeki etkisini incelemektir. Bu kapsamda, dikkat seçiminde öncelik verilen çekici yüzler uyarıcı olarak kullanılmıştır. Toplam 110 gönüllü katılımcının verisi analiz edilmiştir (54 kadın, 56 erkek, Ort $\left.t_{\text {yas }}=20.87 \pm 1.80\right)$. Sonuçta, çekiciliğin $\left[F(2.73,295.16)=37.33, p<.001, \eta_{p}{ }^{2}=.26\right]$ and model cinsiyetinin $\left[F(1,108)=6.47, p<.05, \eta_{p}{ }^{2}=.06\right]$ değişim saptama performansına etkisi anlamlıdır. Buna göre, en hızlı performans sadece hedefin çekici kadın olduğu; en yavaş performans da sadece çeldiricilerin çekici kadın olduğu koşulda gözlenmiştir. Öte yandan, tanıma belleğinin değerlendirilmesinde 94 katılımcının verisi (46 kadın, 48 erkek, Ort $\left.t_{y a s}=21.05 \pm 1.95\right)$ analiz edilmiştir. Buna göre, genel olarak katılımcıların bellek performanslarının kötü olduğu görülmüștür. Özellikle çekici yüzlerde (.31), ortalama yüzlere kıyasla (.59), bellek duyarlılığı oldukça düşüktür. Ayrıca, her iki model cinsiyeti için de çekici yüzlerde "eski" deme yanlılı̆̆ı daha fazladır. Dolayısıyla, karar kriterinin çekici yüzlerde (kadınlar için -.06, erkekler için -.46), ortalama yüzlere kıyasla (kadınlar için .15, erkekler için .33), daha liberal olduğu söylenebilir. Öte yandan, katılımcının cinsiyeti hem dikkat hem de bellek görevinde anlamlı bir etki yaratmamıştır $(p>.05)$. Çalışma, katılımcı cinsiyeti, modelin cinsiyeti ve çekiciliği birarada inceleyen bilinen ilk değişim saptama ve tanıma belleği çalışmasıdır. Çalışmanın sınırlılıkları ve gelecek çalışmalara öneriler tartışma bölümünde ele alınmıştır.

\section{Article History}

Arrived: October 12, 2020

Revised: June 9, 2021

Accepted: June 30, 2021
Author Note: I would like to thank Prof. Dr. Banu (Cangöz) Tavat at Hacettepe University for her valuable guidance. I also thank the editor and reviewers for their careful reviewing and constructive comments. 
Our ancestors managed to survive for a certain period and convince at least one partner to enough sex to fertilize. Those who were not sexually attractive despite their long survival were not our ancestors (Miller, 2000). Evolution is driven by natural selection for survival and sexual selection through mate preference (Darwin, 1859, 1871). So even if a person has a trait that will allow him/her to live forever, this trait cannot spread in the population unless he/she passes this gene on to future generations. Sexual selection is just as crucial as natural selection.

On the other hand, human beings are selective due to limited attentional resources. Selectivity requires prioritization and leads to attentional bias (Corbetta, 1998; Yantis, 2000). For example, the cigarette/alcohol for addictive persons or the picture of a spider for those with specific phobia draws attention automatically (e.g., Bradley et al., 2003; Cisler et al., 2007). Stimuli associated with both natural and sexual selection also lead to this bias. The studies show that life-threatening or negative stimuli such as wild animals, angry faces, or weapons attract attention more strongly (e.g., Amado, Y1ldırım, \& İyilikci, 2011; Biggs, Brockmole, \& Witt, 2013; Heeren et al., 2012; İyilikci, Amado, \& Doğan, 2012; Leleu, Douilliez, \& Rusinek, 2014; Ohman, Flykt, \& Esteves, 2001; Ohman, Lundqvist, \& Esteves, 2001). These studies can be considered examples of attentional bias related to natural selection. Similarly, it is shown that sexually important stimuli, such as attractive faces of the opposite sex, draw attention faster and longer (e.g. İyilikci \& Ertan, 2012; Maner et al., 2007; Maner et al., 2008; Maner et al., 2009; Nakamura \& Kawabata, 2014; van Hooff, Crawford, \& van Vugt, 2011). It can be considered as bias related to sexual selection. Based on these studies, it was decided to take advantage of attractive faces creating automatic attentional bias in the present study. There are few inconsistent findings on the effect of attractive faces on change blindness (e.g., Chen, Liu, \& Nakabayashi, 2012; Duncan et al., 2007). Also, there is no evidence of its effect on unconscious or automatic memory biases. These reasons led to the use of attractive faces. Thus, it was possible to study both the cognitive aspects of sexual selection and the adaptive aspects of attention itself.

Change detection is an important skill for humans (Stolz \& Jolicoeur, 2004). Detecting threatening things or food sources is crucial to stay alive. But sometimes, we cannot see it even though there is an obvious change in our visual area. This detection failure is called change blindness (Rensink et al., 1997; Rensink, 2000a, 2000b; Stolz \& Jolicoeur, 2004). It is often difficult to detect the change if it occurs during a saccade, flicker, or other transients. The difficulty of change detection means that increased change blindness. Although different change detection tasks (e.g., one-shot, mud splats) can sometimes be used in the literature, the flicker task used in the present study is the most commonly used one. In this task, an original image repeatedly alternates with a modified image, with a brief interval between both. The cycle continues for $60 \mathrm{sec}$ or until the participant detects the change (see Rensink et al., 1997).

Attention is the key factor in change detection (O'Regan et al., 2000; Rensink et al., 1997). Detection capability is easily influenced by striking stimuli (Rensink, 2002). The changing of these striking stimuli enhances detection performance (e.g., Jones et al., 2003; Mayer et al., 2006; McGlynn et al., 2008; Yaxley \& Zwaan, 2005). On this basis, in this study, it was examined how to affect the change detection performance by the attractive faces used as target and distractors.

There are very few and inconsistent studies on the effects of facial attractiveness on change detection performance. For instance, Duncan et al. (2007) showed that detection of changes in attractive female faces was faster than in unattractive ones for males. However, Chen, Liu, \& Nakabayashi (2012) showed that attractive faces, regardless of target or distractor, lead to poor detection performance. Firstly, the studies in 
the literature show that the task performance increases when attractive faces are used as a target, and decreases when used as a distractor (e.g., İyilikci \& Ertan, 2012; Maner et al., 2007; Sui \& Lui, 2009). Therefore, the findings of Chen et al. (2012) is quite interesting. On the other hand, the inconsistent findings between these studies mentioned might be due to the task differences. For instance, Duncan et al. (2007) examined the detection of the change in the facial features (e.g. disappearing an eye or a nose), while Chen et al. (2012) examined the detection of the changing face between different faces. The inconsistent findings might be due to this methodological difference.

Furthermore, the effects of participant or model gender have not been examined in the study of Chen et al. (2012), or there is no information about it. However, for males, attractive female faces attract attention faster and longer. On the other hand, the same bias towards attractive faces of the opposite sex is not observed in females (e.g., Maner et al., 2003; Valuch et al., 2015, van Hooff et al., 2011). Based on these covert orienting task studies, it has been predicted that the participant and model gender could also be effective in the change detection task. In addition, whether or not the participant and model gender was considered might have been effective in the inconsistency between the findings of Duncan et al. (2007) and Chen et al. (2012). More studies are needed to understand the gender differences on change detection performance.

In addition to attention, memory studies show that more emotional stimuli are recognized more accurately than neutral ones because these stimuli are primarily processed on an evolutionary basis (e.g., Bradley, Greenwald, Petry, \& Lang, 1992;). On the other hand, the studies using the signal detection approach actually show that emotional stimuli reveal a tendency to say "old" (e.g., Fernandez-Rey \& Redondo, 2007; Ochsner, 2000). A similar memory bias is observed for attractive faces. When the participants know that they will have to recognize the faces later, they remember many more attractive faces than average-looking ones (e.g., Fleishman et al., 1976; Shepherd \& Ellis, 1973). Besides, Marzi \& Viggiano (2010) and DeSimone (2014) showed that attractive and unattractive faces were better recognized than average ones. This also suggests that distinctiveness might be critical on the findings. However, by signal detection approach, Wiese et al. (2014) showed that attractive faces reveal a tendency to say "old". In other words, unattractive faces were better recognized than attractive ones when distinctiveness was controlled. More studies are needed to understand the effect of the level of attractiveness on memory. Moreover, in all these mentioned studies, the participants know to be performed a memory task. In the present study, the effect of attractiveness on memory bias was investigated using a surprise recognition task. The surprise recognition task was preferred to obtain information about whether if the attractive faces are unconsciously and primarily encoded. There is no study that answers whether an advantage or a disadvantage if the coding of attractive faces is an automatic and unconscious. Additionally, it is also controlled for the possible confounding effect of distinctiveness by using structurally similar attractive and average-looking faces. Therefore, it can be said that the findings in this study are more reliable only in terms of revealing the effect of attractiveness.

On the other hand, although it is known that females are better at recognition memory than males (e.g., Becker, Kenrick, Guerin, \& Maner, 2005, McKelvie, 1987), little support is found for the role of gender difference on recognition memory of attractive faces. DeSimone (2014) showed that attractive and unattractive female faces were better recognized than average female ones for both female and male participants. However, only attractive male faces were better recognized than unattractive and average ones. Similarly, Zhang et al. (2016) showed that both females and males had higher accuracy rates for attractive female faces than unattractive ones. Besides, attractive faces elicited larger early components in males than 
in females. However, although Zhang et al. (2016) used the surprise recognition task, female models were only used. Moreover, the memory bias was not evaluated and the possible confounding effect of distinctiveness was not controlled in the mentioned studies. So, that the bias in saying "old" or the high level of distinctiveness for attractive faces might be effective on the findings. Therefore, in this study, examining the effect of participant gender on memory bias (via signal detection) by considering model attractiveness and model gender fills an important gap in the literature.

In summary, the study aims to investigate the effects of the automatic attentional bias caused by the attractive faces in change detection and recognition memory performance. It also examined how participant and model gender affected the performance. It was expected that the attractive faces of the opposite sex would facilitate change detection. Besides, it was expected that there would be more memory bias for attractive faces than the average-looking ones.

\section{Participants}

\section{Method}

A total of 114 participants (57 females, 57 males) from Hacettepe University voluntarily participated in the study. The data of four participants with extreme erroneous responses were excluded from the statistical analysis. Finally, the data of 110 participants (54 females, 56 males) were analyzed. Their age ranged from 18 to 26 years $(M=20.87, S D=1.80)$. All participants were heterosexual and had normal or corrected-to-normal vision.

\section{Stimuli}

The original and modified images were used in the flicker task. The faces were used from HacettepeFaceSet (Ertan-Kaya \& Cangöz, 2019) to create these images. In the set, 26 attractive (13 females, 13 males) and 26 average-looking (13 females, 13 males) faces neutral impressions and no makeup and external features (hair, earring, or piercing). The mean attractiveness levels of attractive females, average-looking females, attractive males, and average-looking males are 5.84, 3.00, 5.76, and 3.01, respectively, on a 7point scale. Besides, image similarity between attractive and average-looking faces was determined by Structural Similarity Index (SSIM, Wang, Bovik, Sheikh, \& Simoncelli, 2004). Accordingly, the SSIM score of the faces in the two categories is .80; that is, they are structurally similar. So, the possible difference cannot be attributed to the more distinctiveness of the faces in any category.

The original image was created by placing six different faces, each located $6^{\circ}$ from the centre of the screen. In the modified image, only one of the six faces from the original image was different (see Figure 1). Both the new face (target) and the distractors (unchanged faces) were attractive in half of the trials and was average-looking in the other half.

\section{Procedure}

The study was approved by the ethics committee of Hacettepe University. Before the experiment, informed consent was obtained from the participants. Then instructions were displayed on the screen. Participants were only given information about the flicker task and not the subsequent recognition task because it was a surprise. After eight practice trials on the flicker task, the main experiment was started. 


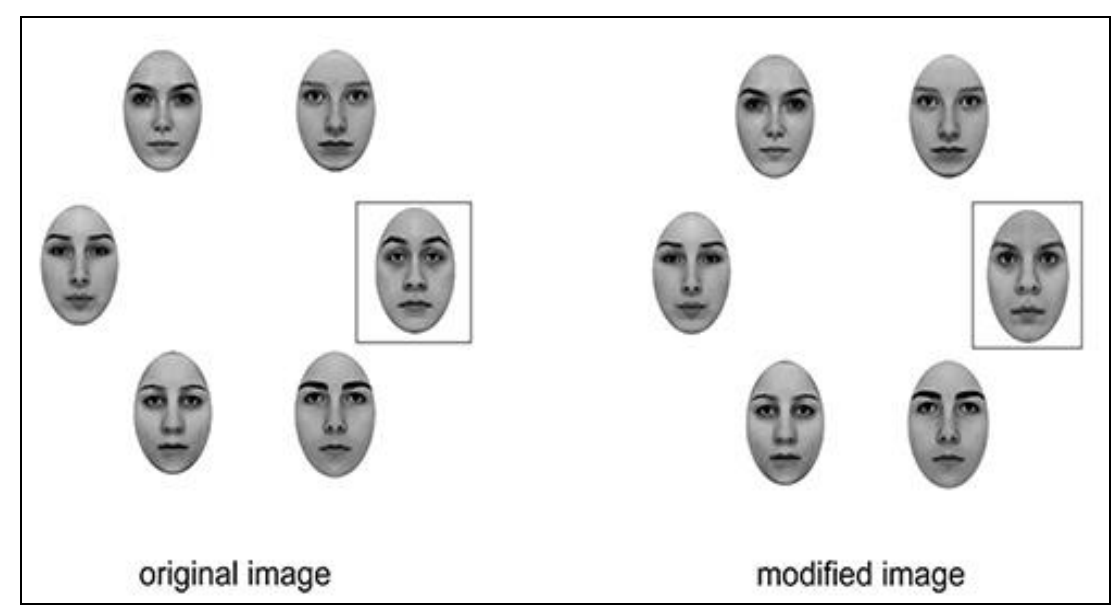

Figure 1. An example of the original and modified images used in the flicker task

In the flicker task, each trial began with a $1000 \mathrm{~ms}$ fixation point. Subsequently, the original image and its modified version were shown for $250 \mathrm{~ms}$, and a blank screen was displayed between these images for $100 \mathrm{~ms}$. The difference between the original and modified images was the change of only one face, which could be placed in any position. The participants were asked to press the space key as quickly as possible after seeing the change. Thereafter, they were asked to determine the position of the changed face as accurately as possible by pressing the designated numbers (see Figure 2).

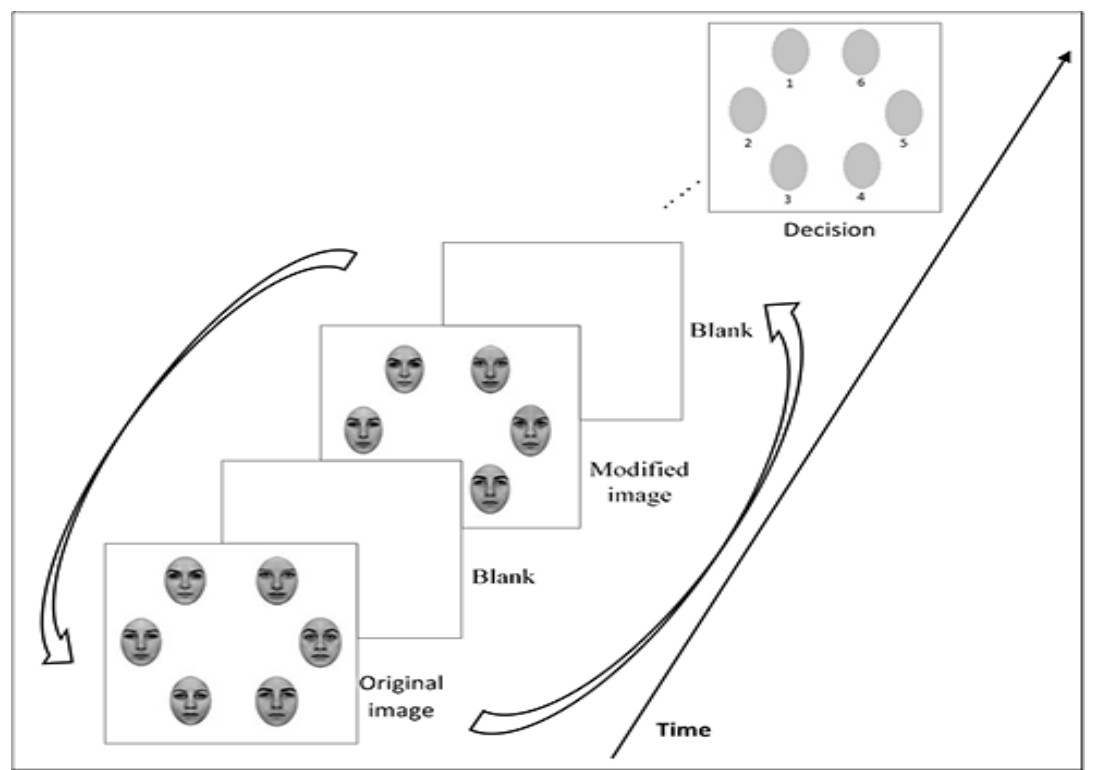

Figure 2. Sample trial in the flicker task.

There were four basic conditions in terms of attractiveness to control the pop-out effects. These conditions were as follows: a) all stimuli were attractive, b) only the target was average-looking and distractors were attractive, c) only the target was attractive, and distractors were average-looking, and d) all stimuli were average-looking. The changed face was referred to as the target. All these conditions were 
presented at random. After the change detection task consisting of the 112 trials (equal numbers of male and female faces were used), a distraction task consisting of simple mathematical operations was presented. The data of the distractor task was not analyzed. Finally, the surprise recognition task, in which 104 faces were displayed on the screen one by one, was presented for the participants who accept to continue the task. The participants were asked to press the designated number if they had seen the faces before. Equal numbers of old and new faces were presented at random. For the participants who did not want to continue, the experiment was terminated without the recognition task.

\section{Results}

\section{Accuracy}

A 4 (Attractiveness) $\times 2$ (Model gender) $\times 2$ (Participant gender) mixed ANOVA was conducted to evaluate the accuracy rate for change detection. As the assumption of sphericity was violated, the $p$-value was adjusted using the Huynh-Feldt correction $(\varepsilon>.75)$.

The results showed significant main effect for attractiveness, $F(2.88,310.98)=8.33, p<.001, \eta_{p}{ }^{2}=$ .07. According to the post hoc analyses (with Bonferroni adjustment), the detection was most accurate when only the target is attractive compared to all other conditions (see Table 1). No other main and interaction effects reached significance $(p>.05)$.

Table 1

Post Hoc Comparisons of Accuracy Rate (\%) for Attractiveness

\begin{tabular}{|c|c|c|c|c|c|c|}
\hline \multirow[b]{2}{*}{ Condition } & \multirow[b]{2}{*}{ Mean } & \multirow[b]{2}{*}{ SE } & \multicolumn{4}{|c|}{ Bonferroni Comparisons } \\
\hline & & & A & $\mathrm{B}$ & $\mathrm{C}$ & $\mathrm{D}$ \\
\hline A & 88.92 & 1.05 & & $p>.05, r=.07$ & $p<.001, r=.26$ & $p>.05, r=.04$ \\
\hline B & 90.25 & .79 & & & $p<.001, r=.19$ & $p>.05, r=.04$ \\
\hline $\mathrm{C}$ & 93.15 & .76 & & & & $p<.001, r=.29$ \\
\hline $\mathrm{D}$ & 89.66 & .91 & & & & \\
\hline
\end{tabular}

Note. Attractiveness conditions are A) all stimuli were attractive, B) only the target was average-looking and distractors were attractive, C) only the target was attractive and distractors were average-looking, and D) all stimuli were average-looking.

\section{Response Time}

A 4 (Attractiveness) $\times 2$ (Model gender) $\times 2$ (Participant gender) mixed ANOVA was conducted to evaluate the response time (RT) for correct change detection. As the assumption of sphericity was violated, the $p$-value was adjusted using the Huynh-Feldt correction $(\varepsilon>.75)$.

The results showed significant main effect for attractiveness $\left[F(2.73,295.16)=37.33, p<.001, \eta_{p}{ }^{2}=\right.$ .26] and model gender $\left[F(1,108)=6.47, p<.05, \eta_{p}{ }^{2}=.06\right]$. Interestingly, changes were detected faster for male models $(M=3712.37, S D=629.30)$ than for female models $(M=3860.95, S D=744.85)(p<.05, r=$ .24). The mean RT results for model gender are shown in Figure 3. Participant gender did not reach significant effect $(p>.05)$. 


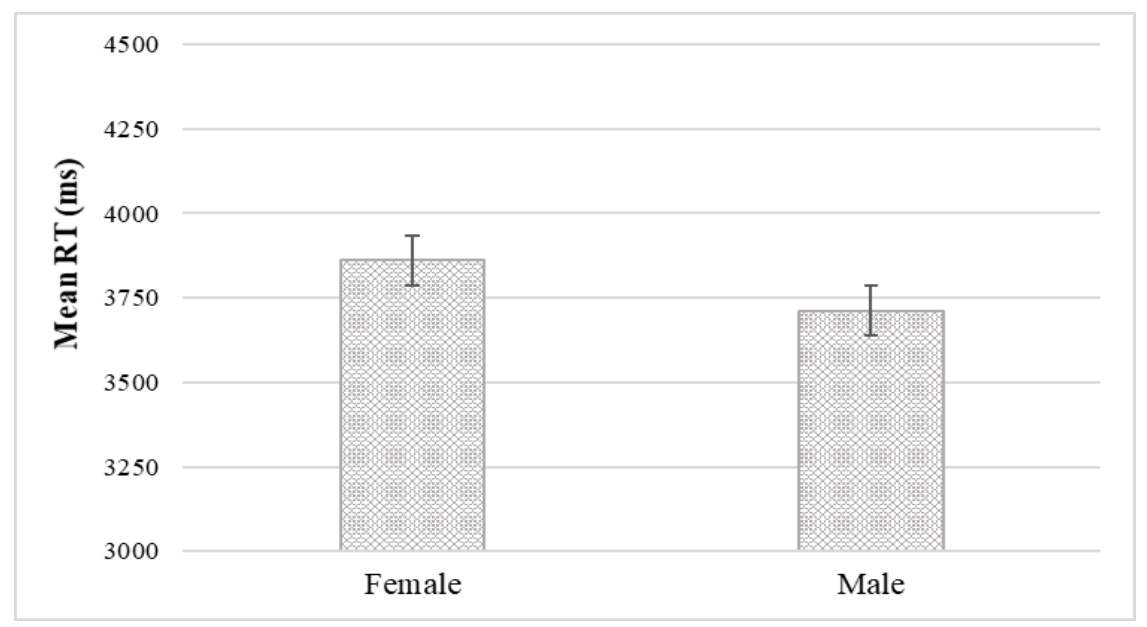

Figure 3. Mean response time of model gender.

For the attractiveness conditions, according to the post hoc analyses (with Bonferroni adjustment), the detection was the fastest when only the target is attractive $(M=3451.77, S D=608.42)$ compared to all other conditions (for only the target was average-looking, $M=4001.45, S D=798.97, p<.001, r=.44$; for all stimuli were attractive $M=3937.83, S D=748.96, p<.001, r=.46$; for all stimuli are average-looking, $M=3755.59, S D=705.06, p<.001, r=.35)$. In addition, the detection when all stimuli were averagelooking was faster than when all stimuli were attractive $(p<.01, r=.19)$. The mean RT results for attractiveness are shown in Figure 4.

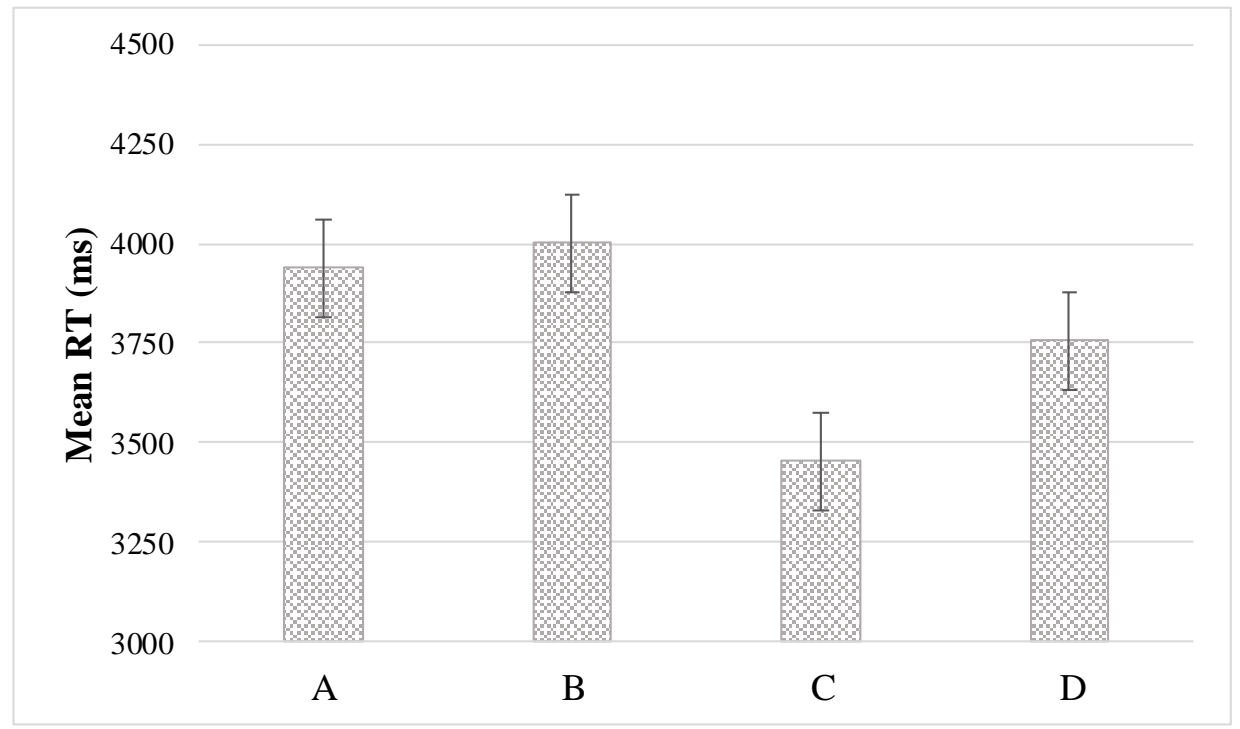

Figure 4. Mean response time of attractiveness. A: all stimuli were attractive, B: only the target was average-looking, C: only the target was attractive, D: all stimuli were average-looking. 
Looking at the interaction effect, the attractiveness*model gender interaction was significant, $F(2.78$, $289.31)=32.29, p<.001, \eta_{p}{ }^{2}=.23$. When only the target was attractive, female models were detected faster $(M=3330.95, S D=786.5)$ than male ones $(M=3572.59, S D=666.29)(p<.01, r=.19)$. However, both when all stimuli were attractive and when only the target was average-looking, male models $(M=3773.93$, $S D=776.19 ; M=3659.44, S D=806.56$, respectively) were detected faster than female ones $(M=4101.73$, $S D=924.01 ; M=4343.46, S D=1074.95$, respectively) $(p<.01, r=.38 ; p<.01, r=.56$, respectively). The mean RT results are shown in Figure 5. No other interaction effects reached significance $(p>.05)$.

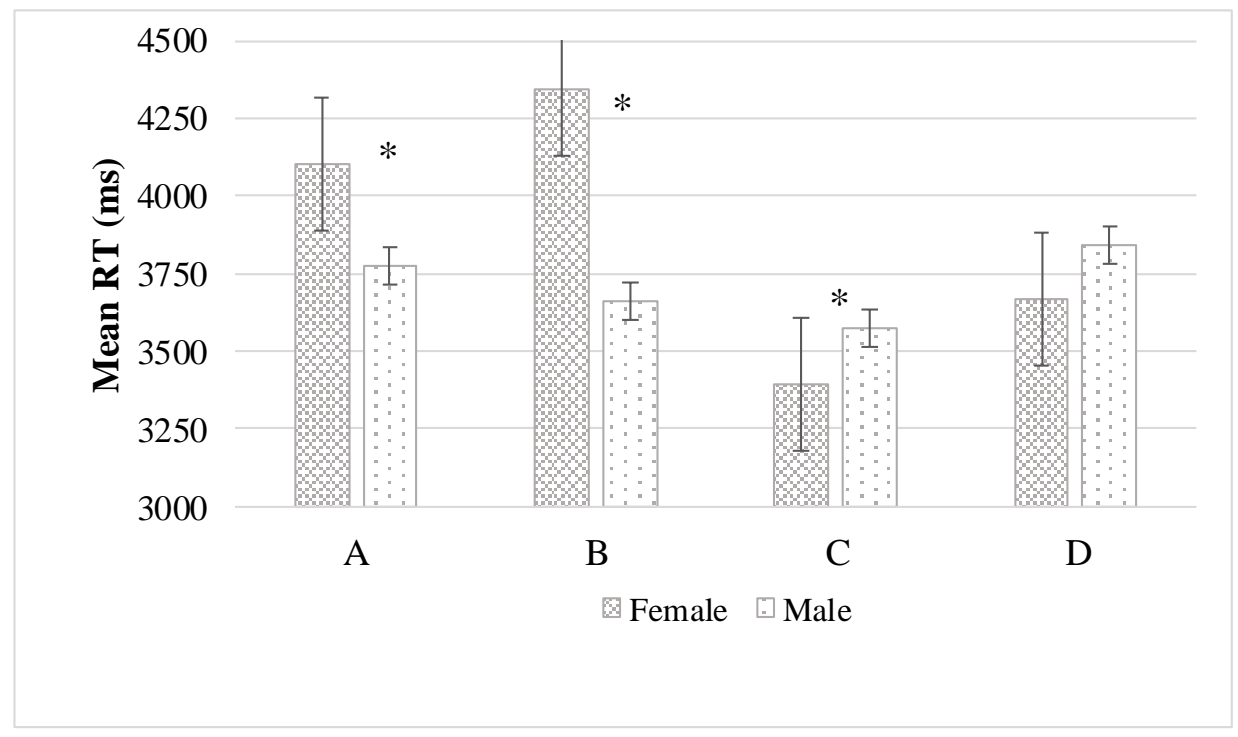

Figure 5. Mean response time of attractiveness*model gender. A: all stimuli were attractive, B: only the target was average-looking, C: only the target was attractive, D: all stimuli were average-looking. $* p<.01$.

\section{Correct Recognition}

The data of five participants with extreme false alarm scores were not included in the recognition memory analysis. Also, 10 participants left in the recognition memory task of the experiment. Thus, the data of 94 participants ( 46 females, 48 males) were analyzed. The mean age of these participants was 21.05 years, and the standard deviation was 1.95 years.

The results summarized in Table 2. A 2 (Attractiveness) x 2 (Model gender) x 2 (Participant gender) mixed ANOVA was conducted on each of $d^{\prime}$ (sensitivity) and $c$ (response bias) values. For $d$ ' values, the results showed significant main effects of attractiveness $\left[F(1,92)=150.52, p<.001, \eta_{p}{ }^{2}=.62\right]$ and model gender $\left[F(1,92)=14.54, p<.001, \eta_{p}{ }^{2}=.14\right]$. Memory sensitivity for the average-looking faces (.59) was significantly higher than for the attractive ones $(-.31)(p<.001, r=.79)$. Besides, memory sensitivity for male models (.25) was significantly higher than female ones $(.03)(p<.001, r=.37)$. Participant gender did not reach significant effect $(p>.05)$.

In addition, there was a significant interaction effect between attractiveness and model gender, $F(1$, $92)=5.56, p<.05, \eta_{p}{ }^{2}=.06$. For attractive faces, there was no difference between female and male models 
$(p>.5)$. On the other hand, for average-looking faces, memory sensitivity for female models (.77) was significantly higher than for male ones $(.41)(p<.001, r=.49)$. No other interaction effects reached significance $(p>.05)$. Furthermore, although there was a significant effect, actually and interestingly, the findings showed that memory performance for all conditions was at chance level due to scores near zero.

For $c$ values, the results showed significant main effects of attractiveness $[F(1,92)=174.25, p<$ $\left..001, \eta_{p}{ }^{2}=.65\right]$ and model gender $\left[F(1,92)=6.30, p<.05, \eta_{p}{ }^{2}=.06\right]$. Bias to respond old for the attractive faces (-.26) was significantly higher than for the average-looking ones $(.24)(p<.001, r=.81)$. Besides, bias to respond old for male models (-.06) was significantly higher than female ones $(.05)(p<.05, r=.25$ ). However, although there was a significant effect, it can be said that model gender-based performance was actually unbiased due to scores very closed to zero.

In addition, there was a significant interaction effect between attractiveness and model gender, $F(1$, $92)=67.31, p<.001, \eta_{p}{ }^{2}=.42$. For attractive faces, bias to respond old for male models (-.46) was significantly higher than female ones $(-.06)(p<.001, r=.53)$. Besides, for average-looking faces, bias to respond old for female models (.15) was significantly higher than male ones $(.33)(p<.001, r=.41)$. No other main and interaction effects reached significance $(p>.05)$.

Table 2

Summary of Recognition Memory Results

\begin{tabular}{|c|c|c|c|c|c|c|c|c|c|}
\hline & & \multicolumn{4}{|c|}{ Male Participants } & \multicolumn{4}{|c|}{ Female Participants } \\
\hline & & Hit rate & FA rate & $d^{\prime}$ & $c$ & Hit rate & FA rate & $d^{\prime}$ & $c$ \\
\hline \multirow{2}{*}{ Attractive } & Female Models & $.45(.19)$ & $.56(.24)$ & -.34 & -.01 & $.48(.20)$ & $.60(.25)$ & -.37 & -.12 \\
\hline & Male Models & $.59(.17)$ & $.68(.18)$ & -.28 & -.40 & $.63(.21)$ & $.71(.21)$ & -.26 & -.52 \\
\hline \multirow{2}{*}{ Average-looking } & Female Models & $.50(.19)$ & $.39(.17)$ & .32 & .15 & $.54(.21)$ & $.36(.18)$ & .50 & .15 \\
\hline & Male Models & $.49(.19)$ & $.28(.16)$ & .65 & .36 & $.55(.20)$ & $.26(.18)$ & .89 & .30 \\
\hline
\end{tabular}

Note: All data are mean values, and standard deviations are in the parenthesis

\section{Discussion}

In the present study, the changes were most accurately detected when the attractive target was shown among average-looking distractors, while the change detection was least accurate when the average-looking target was shown among attractive distractors. The finding supports that attractive faces both draw and hold the attention of the observer for a while. However, this result conflicts with those of Chen et al. (2012). They reported the highest change detection performance when all the stimuli were average-looking and the lowest detection performance when all the stimuli were attractive for undistinctive faces. They concluded that attractive faces attract enough attention to undermine the task. However, the studies in the literature showed if attractive stimuli are used as a target, they can improve the performance (draw attention to the target area). Still, if they are used as a distractor, they can reduce the performance (keep the attention to the non-target area) (e.g., İyilikci \& Ertan, 2012; Manner et al., 2003; Manner et al., 2007, Sui \& Liu, 2009). On this basis, the finding of Chen et al. (2012) is surprising that the fastest performance was not when only the target is attractive. Moreover, the difference between the present study and Chen et al. (2012) cannot be attributed to the distinctiveness of faces. Because attractive and average-looking faces used in this study are similar to each other (SSIM score is .80). 
The response time analysis for change detection implied that the changes were detected the fastest when the attractive target was shown among average-looking distractors. In contrast, the changes were detected most slowly when the average-looking target was shown among attractive distractors. In other words, the attention automatically shifted to attractive faces. When the distractors were attractive, the change detection performance was impaired because of the divided attention. Owing to a lack of an attractive face in the changing location (when the target was average-looking) and the attention-grabbing feature of the attractive distractors might have delayed the focus on the changing location. Here the question can be asked: Why did the pop-out effect not occur? Two points can be made here. Firstly, since average-looking and attractive faces are structurally similar, a pop-out effect is not easy at all. Secondly, even if this effect occurs, the target must keep attention for a while to be detected. Enough time required to detect the average-looking target might be more difficult due to attractive faces around. Furthermore, the fastest performance was not exhibited when all the faces were attractive. Because the probability that the target is primarily focused is $1 / 6$ due to the highly attractive level of all stimuli on the screen.

For RT, the findings of Chen et al. (2012) were still inconsistent with those of Duncan et al. (2007) and the present study. First, they found that change was detected more rapidly in attractive faces, although the study of Duncan et al. (2007) was methodically different and was not directly comparable to this study. Their finding is inconsistent with the findings of Chen et al. (2012), but consistent with the present study in terms of attractive faces improving performance. The fastest performance is when all faces are averagelooking in the study of Chen et al. (2012), whereas only the target is attractive in this study. Furthermore, the change was detected faster in attractive female targets than in attractive male ones. This means that attractive females draw attention more rapidly than attractive males.

On the other hand, model gender was effective on the detection performance in the present study. Male models were detected more rapidly than female ones, regardless of participant gender. Although the outcome seems surprising, it is expected that given the interaction effect between attractiveness and model gender. Accordingly, if only the target is attractive, the female target facilitates the change detection. However, if all faces are attractive or only the distractors are attractive, the female target makes it difficult to detect the changes. This might indicate a tendency to stare at attractive females longer than males. The number of trials in which only the target was attractive was one-quarter of the entire task, resulting in a faster response to males overall. On the other hand, there was no significant effect of participant gender in the present study. There is no study examining model gender, participant gender and change detection together. But, it is showed that attractive female faces attract more quickly and longer attention than attractive male ones for only male participants (e.g., Maner et al., 2003; Valuch et al., 2015, van Hooff et al., 2011). In other words, only males have a bias towards the attractive opposite sex. However, in the present study, attractive female faces are effective on the detection performance for both participant gender. While it is expected that attractive female faces capture the male's attention ( $\mathrm{Lu} \&$ Chang, 2012), it is not also surprising to attract female's attention. Fisher (2004) showed the female intrasexual competition concerning attractiveness. Evolutionary theory predicts that female intrasexual competition occurs when males are considered as a resource (Darwin, 1871). From this perspective, the findings can be interpreted that females are more interested in the attractiveness of the same sex than the opposite sex because of the competition. On the other hand, studies show that mating motivations (e.g. Lu \& Chang, 2012), relationship status (e.g., Maner et al., 2007) or ovulatory status (e.g. Fisher, 2004) of the participants can be effective with respect to attractiveness. It will be interesting for the literature to examine the effects of the socio-demographic characteristics of the participants on the change detection tasks in future studies. 
The correct recognition analysis implied that participants exhibited very poor memory performance. The fact that the $d$ ' values, which show memory sensitivity, are close to zero or even negative, indicate that the task is performed worse than the chance level. The means that participants were not good at making an old and new distinction for attractive faces. Although memory sensitivity for average-looking faces was also low, it outperformed attractive faces. Similarly, memory sensitivity was better for male models. That is, participants were able to distinguish male faces more accurately than females. However, values close to zero suggest that the participants had great difficulty and generally failed in the memory task.

The fact that the task is in the form of surprise recognition can be considered a reason. However, there are similar surprise recognition tasks in the literature (although not with the attractiveness variable). In surprise recognition studies, initial tasks are usually such as matching faces or deciding on gender (e.g. Vuilleumier et al., 2005; Zhang et al., 2016). In these tasks, it is necessary to pay attention to the faces themselves. However, in the change detection task in this study, faces appear and disappear continuously as flashes, that is, intermittent even if they are exposed to the face for a while. Besides, they might not have focused on the details of the face itself to detect the change. Further studies can clarify this issue by examining where they focus on the screen or face using an eye-tracker. On the other hand, this study is still very valuable as it is the first study to examine the effect of participant gender, model gender and attractiveness together. In the future, the same variables can be reexamined with a surprise recognition task followed by the initial task, such as face-matching or gender decision. Another reason for low memory sensitivity might be insufficient trials. Increasing the number of representations for each category will increase the reliability of the results. It might be recommended to repeat the study by increasing averagelooking and attractive faces to see the importance of the number of trials. Besides, in the present study, average-looking and attractive faces were quite structurally similar. This low distinctiveness might be effective on low recognition performance (see DeSimone 2014; Marzi \& Viggiano, 2010). In further studies, it might be suggested to examine the role of distinctiveness on recognition memory in addition to the model gender and attractiveness.

For the $c$ response bias analysis, bias to respond "old" for attractive faces was higher than for average-looking ones. Accordingly, the decision criterion was more liberal for attractive faces than for average-looking ones. However, it can be considered that attractiveness-based performance was weakly biased due to observed $c$ scores near zero (for attractive and average-looking faces, the values are -.26 and .24 , respectively). Besides, male models led to a more liberal criterion than female models for reporting "old" faces. However, it can be said that model gender-based performance was not actually biased (for male and female faces, the values are -.06 and .05 , respectively). On the other hand, the decision criterion was more liberal for attractive males than females (-.46 and -.06, respectively), while it was more liberal for average-looking females than males (.15 and .33, respectively). Besides, the decision criterion was more liberal for attractive faces than average-looking ones for both model genders. This finding is shown that the studies of DeSimone (2014) and Zhang et al. (2016) showed that attractive faces were better recognized than average-looking ones might be misinterpreted. Because the signal detection approach was not used in the mentioned studies. Since they only analyzed hit rates, they could not see the biased responses. Actually, according to the present study, attractive faces do not have better memory performance; on the contrary, there is a high tendency to say old.

In summary, it is valuable in that it is the first known study to examine attractiveness, model gender, and participant gender in terms of both automatic attention and memory bias. Accordingly, in the attentional task (change detection), attractive faces improve performance if it is a target, and impair it if it is a distractor. 
On the other hand, attractive faces impair performance in the memory task (recognition memory) and cause biased responses. In future studies, examining the role of gender and attractiveness on different attention paradigms and memory tasks will shed light on the literature. The present study shows that sexually critical stimuli should also be included in studies as well as vitally critical stimuli.

\section{References}

Amado, S., Yildirim, T., \& İyilikçi, O. (2011). Observer and target sex differences in the change detection of facial expressions: A change blindness study. Cognition, Brain, Behavior: An Interdisciplinary Journal, 15(3), 295-316.

Becker, D. V., Kenrick, D. T., Guerin, S., \& Maner, J. K. (2005). Concentrating on Beauty: Sexual Selection and Sociospatial Memory. Personality and Social Psychology Bulletin, 31(12), 1643-1652. https://doi.org/10.1177/0146167205279583

Biggs, A. T., Brockmole, J. R., \& Witt, J. K. (2013). Armed and attentive: Holding a weapon can bias attentional priorities in scene viewing. Attention, Perception \& Psychophysics, 75, 1715-1724.

Bradley, M. M., Greenwald, M. K., Petry, M. C., \& Lang, P. J. (1992). Remembering Pictures : Pleasure and Arousal in Memory Remembering Pictures: Pleasure and Arousal in Memory. Journal of Experimental Psychology: Learning, Memory, and Cognition, 18(2), 379-390.

Bradley, B. P., Mogg, K., Wright, T., \& Field, M. (2003). Attentional bias in drug dependence: vigilance for cigarette-related cues in smokers. Psychology of Addictive Behaviors: Journal of the Society of Psychologists in Addictive Behaviors, 17(1), 66-72.

Chen, W., Liu, C. H., \& Nakabayashi, K. (2012). Beauty hinders attention switch in change detection: The role of facial attractiveness and distinctiveness. PLOS ONE, 7(2).

Cisler, J. M., Ries, B. J., \& Widner, R. L. (2007). Examining information processing biases in spider phobia using the rapid serial visual presentation paradigm. Journal of Anxiety Disorders, 21, 977-990. http://doi.org/10.1016/j.janxdis.2006.10.011

Corbetta, M. (1998). Frontoparietal cortical networks for directing attention and the eye to visual locations: Identical, independent, or overlapping neural systems? Proceedings of the National Academy of Sciences of the United States of America, 95(February), 831-838.

Darwin, C. (1859). The origin of species by means of natural selection, or the preservation of favored races in the struggle for life. John Murray, Albemarle Street.

Darwin, C. (1871). The descent man, and selection in relation to sex. D. Appleton and Company.

DeSimone, B. M. (2014). The effect of facial attractiveness on recognition memory. Honors Projects Overview, 98. https://digitalcommons.ric.edu/honors_projects/98.

Duncan, L. A., Park, J. H., Faulkner, J., Schaller, M., Neuberg, S. L., \& Kenrick, D. T. (2007). Adaptive allocation of attention: effects of sex and sociosexuality on visual attention to attractive opposite-sex faces. Evolution and Human Behavior, 28, 359-364.

Ebner, N. C., \& Johnson, M. K. (2009). Young and Older Emotional Faces: Are There Age Group Differences in Expression Identification and Memory? Emotion, 9(3), 329-339.

Ertan-Kaya, Ö. \& Cangöz, B. (2019). A Study of Creating Face Photographs Set Including Different Levels of Attractiveness. Archives of Neuropsychiatry, 56(2), 127-132. https://doi.org/10.29399/npa.22923

Fernández-Rey, J., \& Redondo, J. (2007). Recognition memory for pictorial stimuli: Biasing effects of stimulus emotionality. Psicothema, 19(3), 375-380.

Fisher, M. L. (2004). Female intrasexual competition decreases female facial attractiveness. Proceedings of the Royal Society B: Biological Sciences, 271(5), 283-S285. http://doi.org/10.1098/rsbl.2004.0160 
Fleishman, J. J., Buckley, M. L., Klosinsky, M. J., Smith, N., \& Tuck, B. (1976). Judged attractiveness in recognition memory of women's faces. Perceptual and Motor Skills, 43, 709-710. http://doi.org/10.2466/pms.1976.43.3.709

Heeren, A., Peschard, V., \& Philippot, P. (2012). The causal role of attentional bias for threat cues in social anxiety: A test on a cyber-ostracism task. Cognitive Therapy and Research, 36, 512-521. http://doi.org/10.1007/s10608-011-9394-7

İyilikci, O., Amado, S., \& Doğan, A. (2012). Evrimsel Olarak Tehdit Edici Uyarıcıların Değişim Saptama Sürecinde Neden Olduğu Dikkat Yanlılığı ve Yönelme Önceliği, 27(69), 50-61.

İyilikci, O., \& Ertan, Ö. (2012). Yüz Çekiciliğinin Dikkat Yanıp Sönmesi Sürecinde Neden Olduğu Dikkat Yanlılığının İncelenmesi. Türk Psikoloji Yazıları, 15, 52-59.

Jones, B. T., Jones, B. C., Smith, H., \& Copley, N. (2003). A flicker paradigm for inducing change blindness reveals alcohol and cannabis information processing biases in social users. Addiction, 98, 235-244.

Leleu, V., Douilliez, C., \& Rusinek, S. (2014). Difficulty in disengaging attention from threatening facial expressions in anxiety: A new approach in terms of benefits. Journal of Behavior Therapy and Experimental Psychiatry, 45(1), 203-207.

Lu, H. J., \& Chang, L. (2012). Automatic attention towards face or body as a function of mating motivation. Evolutionary Psychology, 10(1), 120-135. http://doi.org/10.1177/147470491201000113

Maner, J. K., Gailliot, M. T., \& DeWall, C. N. (2007). Adaptive attentional attunement: evidence for matingrelated perceptual bias. Evolution and Human Behavior, 28, 28-36.

Maner, J. K., Gailliot, M. T., \& Miller, S. L. (2009). The implicit cognition of relationship maintenance: Inattention to attractive alternatives. Journal of Experimental Social Psychology, 45(1), 174-179. http://doi.org/10.1016/j.jesp.2008.08.002

Maner, J. K., Kenrick, D. T., Becker, D. V., Delton, A. W., Hofer, B., Wilbur, C. J., \& Neuberg, S. L. (2003). Sexually selective cognition: beauty captures the mind of the beholder. Journal of Personality and Social Psychology, 85(6), 1107-1120.

Maner, J. K., Rouby, D. A., \& Gonzaga, G. C. (2008). Automatic inattention to attractive alternatives: the evolved psychology of relationship maintenance. Evolution and Human Behavior, 29, 343-349. http://doi.org/10.1016/j.evolhumbehav.2008.04.003

Marzi, T., \& Viggiano, M. P. (2010). When memory meets beauty: Insights from event-related potentials. Biological Psychology, 84(2), 192-205. http://doi.org/10.1016/j.biopsycho.2010.01.013

Mayer, B., Muris, P., Vogel, L., Nojoredjo, I., \& Merckelbach, H. (2006). Fear-relevant change detection in spider-fearful and non-fearful participants. Journal of Anxiety Disorders, 20, 510-519. http://doi.org/10.1016/j.janxdis.2005.05.001

McGlynn, F. D., Wheeler, S. A., Wilamowska, Z. A., \& Katz, J. S. (2008). Detection of change in threatrelated and innocuous scenes among snake-fearful and snake-tolerant participants: Data from the flicker task. Journal of Anxiety Disorders, 22, 515-523.

McKelvie, S. J. (1987). Sex differences, lateral reversal, and pose as factors in recognition memory for photographs of faces. The Journal of General Psychology, 114(1), 13-37.

Miller, G. (2000). The mating mind: How sexual choice shaped the evolution of the human nature. Doubleday.

Moritz, S., Von Mühlenen, A., Randjbar, S., Fricke, S., \& Jelinek, L. (2009). Evidence for an attentional bias for washing- and checking-relevant stimuli in obsessive-compulsive disorder. Journal of the International Neuropsychological Society: JINS, 15, 365-371.

Nakamura, K., \& Kawabata, H. (2014). Attractive faces temporally modulate visual attention. Frontiers in Psychology, 5, 620. 
Ohman, A., Lundqvist, D., \& Esteves, F. (2001). The face in the crowd revisited: a threat advantage with schematic stimuli. Journal of Personality and Social Psychology, 80(3), 381-396.

Ohman, A., Flykt, A., \& Esteves, F. (2001). Emotion drives attention: detecting the snake in the grass. Journal of Experimental Psychology. General, 130(3), 466-478.

O’Regan, K. J., Deubel, H., Clark, J. J., \& Rensink, R.A. (2000). Picture Changes During Blinks: Looking Without Seeing and Seeing Without Looking. Visual Cognition, 7, 191-211.

Ochsner, K. N. (2000). Are affective events richly recollected or simply familiar? The experience and process of recognizing feelings past. Journal of Experimental Psychology: General, 129(2), 242261. https://doi.org/10.1037/0096-3445.129.2.242

Rensink, R. A. (2000a). Seeing, sensing, and scrutinizing. Vision Research, 40, 1469-1487.

Rensink, R. A. (2000b). Visual Search for Change: A Probe into the Nature of Attentional Processing. Visual Cognition, 7, 345-376. http://doi.org/10.1080/135062800394847

Rensink, R. A. (2002). Change Detection. Annual Review of Psychology, 53, 245-277.

Rensink, R. A., Regan, J. K. O., \& Clark, J. J. (1997). To See Not To See: the need for attention to perceive changes in scenes, Psychological Science, 8(5), 368-373.

Renwick, B., Campbell, I. C., \& Schmidt, U. (2013). Attention bias modification: A new approach to the treatment of eating disorders? International Journal of Eating Disorders, 46, 496-500. http://doi.org/10.1002/eat.22107

Shepherd, J. W., \& Ellis, H. D. (1973). The effect of attractiveness on recognition memory for faces. The American Journal of Psychology, 86(3), 627-633.

Stolz, J. A, \& Jolicoeur, P. (2004). Changing features do not guide attention in change detection: evidence from a spatial cueing paradigm. Psychonomic Bulletin \& Review, 11(5), 870-875.

Sui, J., \& Liu, C. H. (2009). Can beauty be ignored? Effects of facial attractiveness on covert attention. Psychonomic Bulletin \& Review, 16(2), 276-281. https://doi.org/10.3758/pbr.16.2.276

Valuch, C., Pflüger, L. S., Wallner, B., Laeng, B., \& Ansorge, U. (2015). Using eye tracking to test for individual differences in attention to attractive faces. Frontiers in Psychology, 6(42), 1-13. http://doi.org/10.3389/fpsyg.2015.00042

van Hooff, J. C., Crawford, H., \& van Vugt, M. (2011). The wandering mind of men: ERP evidence for gender differences in attention bias towards attractive opposite sex faces. Social Cognitive and Affective Neuroscience, 6, 477-485.

Vuilleumier, P., George, N., Lister, V., Armony, J., \& Driver, J. (2005). Effects of perceived mutual gaze and gender on face processing and recognition memory. Visual Cognition, 12(1), 85-101.

Wang, Z., Bovik, A. C., Sheikh, H. R., \& Simoncelli, E. P. (2004). Image quality assessment: From error visibility to structural similarity. IEEE Transactions on Image Processing 13(4), 600-612.

Wiese, H., Altmann, C. S., \& Schweinberger, S. R. (2014). Effects of attractiveness on face memory separated from distinctiveness: Evidence from event-related brain potentials. Neuropsychologia, 56, 26-36.

Yantis, S. (2000). Goal-directed and stimulus-driven determinants of attentional control. Control of Cognitive Processes: Attention and Performance XVIII, 73-103.

Yaxley, R. H., \& Zwaan, R. A. (2005). Attentional bias affects change detection. Psychonomic Bulletin \& Review, 12(6), 1106-1111. http://doi.org/10.3758/BF03206451.

Zhang, Y., Wei, B., Zhao, P., Zheng, M., \& Zhang, L. (2016). Gender differences in memory processing of female facial attractiveness: Evidence from event-related potentials. Neurocase, 22(3), 317-323. 